\title{
GOVERNO FHC E ESTRATÉGIA DE PARCERIA: RETOMANDO A ANÁLISE CRÍTICA DO PROGRAMA COMUNIDADE SOLIDÁRIA ${ }^{1}$
}

Oleg Abramov ${ }^{2}$

\begin{abstract}
RESUMO
O texto objetiva retomar, segundo uma perspectiva crítica, a análise da estratégia de parceria desenvolvida no âmbito da agenda social do governo Fernando Henrique Cardoso. O aporte teórico empregado deriva do neoinstitucionalismo histórico e o foco se concentra no desenho, pressupostos, intenções verdadeiras, efeitos concretos e trajetória do Programa Comunidade Solidária. Através dele, objetivava-se introduzir uma modalidade de política pública adequada aos imperativos da ortodoxia macroeconômica imperante à época e estimular uma nova modalidade de intervenção social de perfil caritativa. Demonstra-se que o Programa produziu impacto insuficiente nos dilemas que pretendia enfrenta o que acarretou sua superação.

Palavras-chave: Governo FHC; Programa Comunidade Solidária; Terceiro Setor.
\end{abstract}

\begin{abstract}
The paper aims to review, from a critical perspective, the analysis of the partnership strategy developed within the social agenda of the Fernando Henrique Cardoso government. The theoretical contribution derives from the historical neoinstitutionalism and the focus is on the design, assumptions, true intentions, concrete effects and trajectory of the Community Solidarity Program. Through it, the objective was to introduce a modality of public policy adequate to the imperatives of macroeconomic orthodoxy prevailing at the time and to stimulate a new modality of social intervention of charitable profile. It is demonstrated that the Program produced insufficient impact in the dilemmas that it was facing that brought about its overcoming.
\end{abstract}

Keywords: Government FHC; Community Solidarity Program; Third Sector.

\section{RESUMEN}

El texto pretende reanudar, de acuerdo con una perspectiva crítica, el análisis de la estrategia de asociación desarrollado bajo la agenda social del gobierno de Fernando Henrique Cardoso. El marco teórico utilizado se deriva del institucionalismo histórico y la atención se centra en el diseño, suposiciones, intenciones verdaderas, el impacto y la trayectoria del Programa Comunidad Solidaria. A través de su objetivo era introducir una forma de política pública adecuada a las exigencias de la ortodoxia macroeconómica prevaleciente en el momento y fomentar una nueva forma de intervención social perfil de caridad. Se muestra que el programa ha producido un efecto insuficiente sobre los dilemas que significaban caras que llevaron superación.

Palabras-clave: FHC gobierno; Programa Comunidad Solidaria; Tercer sector.

\section{INTRODUÇÃO ${ }^{3}$}

O texto objetiva analisar a estratégia de parceria desenvolvida no âmbito da agenda social do governo Fernando Henrique Cardoso. Para tanto, o foco se concentra no desenho,

\footnotetext{
${ }^{1}$ Enviado em: 01/10/2016

Aceito para publicação em: 09/12/2016

${ }^{2}$ Doutorando em Ciências Sociais pela Universidade Federal de Juiz de Fora na linha de Políticas Públicas e Desigualdade Social. Possui Graduação em História pela UFJF (2003) e Mestrado em Ciências Sociais também pela UFJF (2009). Realiza pesquisas na área de Ciência Política, com ênfase em Políticas Públicas, especialmente de recorte social, Política Comparada e Sistemas de Bem-Estar (políticas regulatórias no campo do trabalho, Previdência, Saúde e Assistência). Possui especializações em História do Brasil, História Econômica e Planejamento e Gestão Social. Foi bolsista do Programa de Pós-Graduação em Ciências Sociais, participa de duas pesquisas financiadas pelo CNPq, e atua profissionalmente como docente. Atualmente é Superintendente Regional de Saúde, da Secretaria de Estado de Saúde de Minas Gerais. E-mail: oleg.pt.cut@gmail.com

${ }^{3}$ Uma versão preliminar deste texto foi apresentado no $3^{\circ}$ Fórum Brasileiro de Pós-Graduação em Ciência Política - UFPR, Curitiba, 2013.
} 
pressupostos, intenções verdadeiras, efeitos concretos e trajetória do Programa Comunidade Solidária.

Pretende-se explorar particularmente seu alcance na efetivação da disposição de impulsionar um sugerido "setor público não-estatal" no Brasil. A ênfase que o neoinstitucionalismo histórico confere às instituições e seus efeitos condicionadores de escolhas, ações e práticas sociais servem de referência teórica para o presente trabalho.

Justifica-se a retomada da análise de uma instituição após 14 do encerramento de seus trabalhos pela necessária preservação da memória, mesmo de estratégias fracassadas, e pela conjuntura política atual, caracterizada pela instalação de um governo alinhado à agenda efetivada nos anos FHC. É presumível que no rastro do retorno da política privatizante, modalidades de políticas sociais restritas à contenção orçamentária retornem à agenda. Neste sentido, para além de empreender a análise de um caso que demonstra os efeitos que uma instituição formal é capaz de efetivar na organização da sociedade e da maneira como determinadas estratégias sociais são menos efetivas no enfrentamento a dilemas que supostamente buscavam superar, também serve ao propósito de cultivar a memória de experiências do passado recente para compreender propósitos e efeitos práticos de determinadas modalidades de estratégias de intervenção social que podem retornar à agenda do Governo Federal.

O trabalho está organizado em quatro seções. Imediatamente abaixo é apresentado o desenho do Programa, na seção seguinte são verificados os pressupostos teóricos e a sua finalidade em relação ao desenvolvimento da estratégia de parceria, na sequencia são analisadas alguns resultados da ação efetivada para finalmente refletir sobre suas debilidades.

\section{COMUNIDADE SOLIDÁRIA: OBJETIVO OFICIAL, ARMAÇÃO INSTITUCIONAL E AÇÃO}

O Programa Comunidade Solidária pretendia dar sequencia a agenda inaugurada pelo Conselho de Segurança Alimentar (CONSEA) efetivado no governo Itamar Franco (PELIANO, RESENDE e BEGHIN, 1995). Além de ser composto por parte governamental e representação da sociedade civil, ele foi o responsável pela introdução do tema Segurança Alimentar efetivada através da articulação público-privada, parceria, solidariedade e descentralização. Sob coordenação de um Conselho, objetivava alavancar ações governamentais segundo o diagnóstico definido pelo "mapa da fome" elaborado pelo Instituto de Pesquisa Econômica Aplicada (IPEA) e objetivando diretrizes fixadas pelo Plano de Combate à Fome, à Miséria e pela Vida (PCFM) (PERES, 2005). 
ABRAMOV, Oleg. Governo FHC e estratégia de parceria: retomando a análise crítica do programa Comunidade Solidária

O Comunidade Solidária foi criado em 1995 pelo decreto presidencial $\mathrm{n}^{0} 1.366$, de 12 de janeiro, cuja a base teórico-legal, segundo Peres (2005), deita raízes no projeto de reforma administrativa que propunha a criação de instituições normativas e organizacionais que alterassem o padrão de gestão pública, transitando de um modelo burocrático para o de perfil gerencial. Embora denominado "programa”, seu formato era o de órgão responsável por promover uma estratégia de articulação entre níveis governamentais e entre a administração pública e entidades não governamentais (SILVA, GUILHON, CRUZ e DA SILVA, 2001).

Seus documentos oficiais determinavam como princípios a parceria entre governo e sociedade civil, solidariedade, descentralização e convergência integrada de ações. Os objetivos gerais definidos eram otimizar o gerenciamento de programas federais através da participação da sociedade no controle e execução; incorporar, potencializar e apoiar programas impulsionados pela sociedade ou governos locais em áreas de concentração de pobreza; e propor novas prioridades, elaborando propostas de ação para governos e sociedade em relação a temas emergenciais e grupos vulneráveis. Como desdobramento destes três, seus propósitos específicos eram promover redução da mortalidade infantil, melhorar a alimentação nas escolas, melhorar condições de saneamento e moradia, aperfeiçoar condições de vida no meio rural, gerar emprego, renda e qualificação profissional, apoiar medidas no sentido de promover desenvolvimento da educação infantil e do ensino fundamental e, por fim, defender direitos e promover socialmente crianças e adolescentes (PELIANO, RESENDE e BEGHIN, 1995; SILVA, GUILHON, CRUZ e DA SILVA, 2001).

Seu desenho institucional comportava quatro níveis: o Conselho Consultivo, a Secretaria Executiva, Ministérios Setoriais e Interlocutores Estaduais. Os penúltimos eram as Pastas Ministeriais que compunham o Conselho Consultivo e que deveriam priorizar os investimentos indicados e os últimos eram escolhidos pelos governos de cada Estado para serem os responsáveis pelo diálogo direto com o governo federal. Os dois outros figuram como organismos próprios do Programa.

Tal como o CONSEA, os membros do Conselho Consultivo eram nomeados pelo Presidente da República, sendo onze ministros, vinte e um representantes da sociedade e os membros da secretaria executiva. No decorrer de sua história, sua composição foi modificada. Em toda sua trajetória, o Conselho manteve-se presidido pela Primeira Dama e principal animadora do projeto, a antropóloga Ruth Cardoso. No organograma do Executivo, o órgão encontrava-se subordinado ao Ministério da Casa Civil. Suas atribuições eram basicamente sugerir iniciativas e ajudar na articulação, execução e publicização de suas ações. 
A Secretaria Executiva tinha como função coordenar as ações do governo na área social em assessoramento à Casa Civil, contando com o apoio do Ministério do Planejamento Orçamentário, em particular por meio do IPEA, não gozando de recursos próprios e sem quaisquer atribuições executavas. Sua ação limitava-se a repassar aos Ministérios as deliberações do Conselho Consultivo e supervisionar projetos. Eram três seus objetivos: encaminhar o selo de prioridade realçando quais iniciativas deveriam ter preferência no aporte de recursos de outros ministérios; buscar produzir integração e convergência das ações nos municípios pobres; e construir a parceria com a sociedade civil. A última meta era efetivada de duas maneiras: primeiramente, mobilizando recursos humanos, materiais e financeiros voltados a demandas não atendidas por recursos federais; além dessa, estimulando a criação de instâncias estaduais de articulação com a sociedade civil (PELIANO, RESENDE e BEGHIN, 1995; PERES, 2005).

Os recursos utilizados ou alocados pelo Comunidade Solidária possuíam fontes públicas e privadas. A primeira era, principalmente, originada do orçamento da União, Fundo de Amparo ao Trabalhador e Fundo de Garantia por Tempo de Serviço, além de fontes estaduais e municipais. A segunda era arrecadada de empresas privadas, agências nacionais e internacionais de financiamento e cooperação, sindicatos, associações, universidades, igrejas e pessoas físicas (PELIANO, RESENDE e BEGHIN, 1995).

Quando o governo FHC se aproximava do fim, as principais lideranças do Comunidade Solidária fundaram uma nova organização totalmente desligada do Governo Federal denominada Comunitas: parcerias para o desenvolvimento solidário e criaram a Rede Sol, buscando manter uma rede interligando os projetos e programas promovidos e apoiados pelo Comunidade.

Em alinhamento com seus princípios, as iniciativas impulsionadas pelo Programa eram baseadas em parcerias na alocação de recursos e envolvimento voluntário. Buscavam autonomia e descentralização e contavam com apoios externos ao poder público, tais como de ONGs, associações comunitárias, universidades e empresas. Suas iniciativas mais destacadas foram: o Programa Universidade Solidária; o Programa Capacitação Solidária; o Alfabetização Solidária; o Programa Artesanato Solidário e o Rede Jovem.

Simultaneamente adotou iniciativas no sentido de fortalecer as organizações da sociedade civil que contaram com o financiamento do Banco Interamericano de Desenvolvimento, o apoio da UNESCO e da Fundação Banco do Brasil e se concentraram em três frentes: revisão do marco legal que regulamenta o assim chamado "terceiro setor", 
ABRAMOV, Oleg. Governo FHC e estratégia de parceria: retomando a análise crítica do programa Comunidade Solidária

estímulo ao trabalho voluntário através de iniciativas como o Programa Voluntários e da Rede de Centros de Voluntariado e a disseminação de informações sobre o "terceiro setor".

Uma das principais iniciativas neste campo foi a promoção de interlocução política com a finalidade de propor mudanças na legislação, objetivando conferir um moderno marco legal às iniciativas não governamentais. Dentre suas propostas, encontram-se a regulamentação do trabalho voluntário e das organizações sem fins lucrativos, temas detalhados adiante. Também impulsionou outras iniciativas voltadas ao desenvolvimento do "terceiro setor", tais como o apoio à criação de centros voluntários, o lançamento do Portal do Voluntariado e a criação da Rede de Interlocução do Terceiro Setor.

Definidos os contornos institucionais do Programa, na sequencia será analisado o que se sugere estar por trás do discurso oficial, elencando os pressupostos implícitos que se encontra subjacente a sua ação.

\section{COMUNIDADE SOLIDÁRIA: PRESSUPOSTOS E OBJETIVOS ANUNCIADOS E VERDADEIROS}

\subsection{Debatendo os pressupostos implícitos}

Ao refletir sobre o discurso de intelectuais notoriamente envolvidos com o Comunidade Solidária e suas prioridades de ação é possível determinar os pressupostos que o orientam.

Do ponto de vista de Ruth Cardoso (1995; 2005), idealizadora e dirigente do Programa, considerava que os movimentos sociais que emergiram após o Regime Militar eram excessivamente ideológicos e partidarizados, contrastando com as associações nãogovernamentais. Voltadas à resolução de dilemas públicos, tais apresentavam-se como um aperfeiçoamento da dimensão organizativa da sociedade, posto que não concorriam ou disputavam com o poder político e se baseavam em valores. Segundo ela, o trabalho voltado ao bem comum constituia o cerne de uma nova concepção de cidadania na qual a emancipação humana seria obra da ação conjunta de atores diversos.

No lugar da luta política e ideológica voltadas à transformação social, estaria emergindo um novo espaço de sociabilidade que superaria a incapacidade do Estado e os limites do mercado. Para relevante parte dos defensores da novidade, tal seria designado como "terceiro setor" uma vez que ocuparia o espaço e diverso com o mercado e do Estado. Ainda segundo Ruth Cardoso (2005), seu caráter é autônomo e inédito. Para ela, seu mérito era o de romper com a dicotomia público versus privado, enriquecendo a dinâmica social. As 
associações sem fins lucrativos em geral são relacionadas a um sentimento "solidário" ou uma "postura cidadã" por parte dos agentes "voluntários" envolvidos. O pano de fundo é a busca pela unidade de todos em torno de causas comuns que transcendem posições sócioeconômicas ou corporativas.

Rubem César Fernandes (1994 e 2005), um dos mais consultados autores do "terceiro setor" e membro ativo do Conselho Consultivo do Comunidade Solidária, afirmava que os anos de ditadura acabaram incutindo em muitas das associações um caráter avesso ao poder político. Para ele, quando os canais de articulação verticais deixaram de integrar a sociedade e o Estado, a comunidade passou a distanciar-se da política, ou, pelo menos, da política formal. Como o Estado parecia inacessível, o horizonte destas associações passava a limitar-se ao "local" e ao "possível". Com a queda do comunismo e a desideologização da luta política, esta tendência passava a tornar-se dominante, e a opção por mudanças revolucionárias ou radicais foram definitivamente derrotadas pela preferência de focar em melhorias pontuais e rápidas, resultantes da intervenção prática e imediata.

Ao lado da noção de colapso do paradigma soviético - o que leva Fernandes a concluir pelo colapso de qualquer paradigma alternativo ao capitalismo - , situa-se a crise do Estado, pelo menos do Estado característico do pós-Segunda Guerra, tido como burocrático e ineficiente. Para Naves (2003), o que fomenta o desenvolvimento do "terceiro setor" é a compreensão de que, em décadas recentes, na mesma proporção que os direitos humanos vão sendo progressivamente valorizados, o Estado vai perdendo sua capacidade de garanti-los, devido a sua crise estrutural, relacionada ao esgotamento financeiro.

Bresser-Pereira ${ }^{4}$ e Grau (1999) propõem as iniciativas "públicas não-estatais" na condução de políticas sociais como alternativa a incapacidade do Estado. Segundo eles, o Estado social-liberal se afirmaria mais flexível na provisão de serviços sociais, na medida em que, ao invés de executar sozinho, passava a financiar parte dos programas e projetos que podem ser desenvolvidos por organizações mais eficientes, imersas na competição do mercado, mas que primam por valores públicos. Este é o conteúdo da reforma gerencialista objetivada nos anos FHC.

O que se extrai até aqui dos idealizadores da modalidade de intervenção social efetivado pelo Comunidade Solidária é o fato de se basearem em um certo tipo de concepção de relações sociais, fundado na objeção à luta por qualquer alternativa ao modelo econômicosocial vigente e calcada na compreensão de que é possível produzir colaboração em torno da

\footnotetext{
${ }^{4}$ Além de teórico, Ministro de FHC à frente da pasta responsável por promover a reforma gerencialista do Estado.
} 
ABRAMOV, Oleg. Governo FHC e estratégia de parceria: retomando a análise crítica do programa Comunidade Solidária

agenda social entre atores cuja relação pode ser conflituosa em outras arenas. Além disso, o horizonte de uma mudança social mais profunda é suprimido em favor da prática imediata, focal e pouco abrangente.

Para Demo (2001), o discurso da solidariedade da maneira como é construído objetiva esconder os processos de dominação e os conflitos sociais entre capital e trabalho. Buscava-se criar uma falsa atmosfera de cooperação para acalmar os choques de classes, criando um ambiente propício para a recuperação do mercado. Souza (2001) segue a mesma linha ao afirmar que a noção de solidariedade constitui-se em uma ideologia que mascara as possibilidades de enfrentamento entre atores sociais distintos, e oculta a existência de dominação. A parceria tal como desenvolvida, leva ao alinhamento de grupos sociais distintos em torno de interesses homogêneos, o que ordena as relações sociais de forma a minimizar divergências e, na prática, conduz a uma subordinação de toda a sociedade aos interesses dominantes. No lugar de reivindicar e exigir o cumprimento das responsabilidades governamentais, caberia, nessa suposta nova ordem, apenas fazer o "possível", o que "está ao alcance". Além disso, Teodósio (2002) e Soares (2004) avaliam os riscos inerentes à "captura" dos movimentos sociais por parte das instituições estatais e privadas, tais como a reedição do clientelismo.

Campos (1995) julga o princípio da solidariedade subjacente ao Comunidade Solidária como sendo um componente que objetiva deslocar a responsabilidade do Estado para a sociedade. Na ótica dos autores do "terceiro setor", a premissa é de que existe uma tensão entre Estado e sociedade civil. Enquanto se replica o argumento de matriz liberal segundo o qual o Estado é tido como incapaz, ineficiente, oneroso e corrupto, a sociedade civil emerge correspondendo à utopia da unidade de todos que, movidos por princípios, aliam-se em torno de causas comuns consensualmente admitidas como prementes. A sociedade civil, tal como descrita, exerce um papel autônomo e tem condições de fazer aquilo que o Estado não pode, ou não admite como prioridade: realizar políticas públicas sociais eficientes. Neste caso, o Estado só é admitido enquanto um parceiro que ajuda no financiamento de certos programas de impacto social.

A narrativa de oposição ao Estado, reconhece que o mercado é incapaz de regular por si só a vida social. Porém, não há qualquer engajamento no sentido de limitar os efeitos perversos de sua operação, pelo contrário, Bresser Pereira e Grau (1991), por exemplo, atribuem vantagem às organizações sem fins lucrativos exatamente devido às práticas herdadas das empresas privadas que as torna mais ágeis e eficientes. O mercado não é 
responsável pelo enfrentamento dos dilemas sociais gerados por ele mesmo e suas práticas são exaltadas como aquelas portadoras da racionalidade e eficiência necessárias para responder às assimetrias que produz. Dessa forma, a operação de mercado ao mesmo tempo é desresponsabilizada e legitimada. A compreensão de que o mercado não está voltado a ser espaço de resolução de problemas sociais é uma ressalva diferente daquela feita ao Estado. $\mathrm{O}$ mercado é justificavelmente orientado para o lucro e é eficiente, o Estado deveria ser orientado para o bem-estar, mas é incapaz de cumprir sua vocação, pior, sua corrupção supostamente inerente não poucas vezes é ressaltada como geradora de distorções. Há evidente opção por minimizar os outcomes perversos do mercado e exaltar as contradições do Estado.

\subsection{Debatendo o objetivo de construir o "terceiro setor"}

Skocpol $(1985 ; 1995)$ e outros autores neoinstitucionalistas históricos enfatizam o fato de que da mesma forma que o Estado sofre pressão de agentes e grupos sociais, ele também tem a capacidade de moldar padrões de intervenção social, especialmente ao estabelecer enredamentos institucionais, produzindo restrições ou introduzindo incentivos à determinadas práticas. Verificada a narrativa que o envolve, não é exagero avaliar que a meta mais importante do Comunidade Solidária e sua maior novidade, como explicitam seus idealizadores, era buscar ser o articulador do desenvolvimento de iniciativas públicas independente do Estado.

Apresentava-se como aquele que teria a finalidade de constituir um novo padrão de relacionamento que pudesse resultar em programas voltados ao desenvolvimento social executados em parceria, para tanto era premente ajudar a desenvolver a contraparte, o “terceiro setor". Não é por acaso que junto ao Programa Universidade Solidária, uma de suas primeiras iniciativas foi o Programa de Fortalecimento da Sociedade Civil. Ainda em novembro de 1995, as bases desse projeto já haviam sido lançadas em um seminário nacional realizado em Brasília com a presença de diversas entidades do "terceiro setor" e resultou em uma elaborada e extensa agenda com iniciativas de fortalecimento de suas organizações e da participação cidadã.

Dada a importância conferida ao fenômeno e sua fluidez conceitual torna-se premente que se responda à questão de qual é a perspectiva que o Comunidade Solidária possui do que seja o "terceiro setor". 
ABRAMOV, Oleg. Governo FHC e estratégia de parceria: retomando a análise crítica do programa Comunidade Solidária

Os conceitos relacionados à ideia do "público não-estatal", a começar pela expressão adotada, são amplos, imprecisos e até contraditórios. Percebe-se que a literatura disponível mais confunde que elucida. Não há acordo sobre as entidades que o compõem, sobre sua origem, ou mesmo sobre o termo que melhor designa as atividades "não-lucrativas" e "nãoestatais" vinculadas ao "bem público". Por exemplo, Fernandes (1994) inclui os sindicatos no público não estatal, já Bresser-Pereira transporta-os para a esfera corporativa. Coelho (2002) e Albuquerque (2006) remontam-se aos séculos XVI e XVII para explicar a origem do fenômeno, Cardoso (2005) acredita ser algo completamente novo. Os apoiadores do Comunidade em geral, a começar por Fernandes (1994), emprega o termo "terceiro setor", diferentemente de Bresser-Pereira e Grau que o substitui pela expressão "esfera pública nãoestatal". Não há sequer uma definição comum do que vem a ser e qual a verdadeira motivação do tema em questão.

Tal controvérsia revela a dificuldade de operar com base em uma categoria difusa e contraditória. Mais ainda, produz a indagação: em meio a tamanha diversidade quais exatas organizações e ações o Comunidade Solidária buscava beneficiar?

Refletindo sobre a proposição oficial do Programa, identifica-se duas frentes de atuação. A primeira diz respeito à mobilização de cidadãos atomizados em torno de causas tais como a alfabetização e o combate a fome, a segunda envolve o impulso a instituições que se identificam com valores solidários, empregam trabalho voluntário, agem no sentido de prover bens e serviços de assistência aos afligidos sem operar no mercado a priori ou estar contido em organogramas governamentais.

Essas considerações implicam em perceber que, diferentemente do que sugere o discurso sobre o "setor sem fins lucrativos" emergente, não é possível dizer que toda organização não governamental esteja no arco de parceiros potenciais do Comunidade Solidária. Existem aquelas que praticam assistência e as que se orientam para agir no sentido da concretização de causas. As segundas, embora sejam reivindicadas pelo "terceiro setor", possuem uma perspectiva bem diversa àquela que o Comunidade procura incrementar. Tais organizações não atendem a necessitados, mas exigem dos órgãos competentes, em particular do Estado e, assim, traduzem um deslocamento em relação aos pressupostos do Programa. O sentido da ação é explicitamente destoante: enquanto certas organizações agem por si mesmas e em algum nível "negam" o Estado estas “organizações ativistas”, não produzem bens ou serviços públicos, mas dirigem-se aos órgãos competentes reivindicando decisões. Seria um exemplo de organização ativista o Greenpeace, que como ONG critica a ação, ou negligência, 
dos governos para com o problema ambiental e não recua na perspectiva de pressionar o poder público no plano nacional e mundial para que tome medidas voltadas à preservação da natureza.

Estas organizações não são objeto de atenção do Comunidade Solidária. A despeito de ter patrocinado alguns debates sobre meio ambiente e questão agrária (LOBO, 2002), não são essas, nem suas atividades, que mereceram a atenção ou investimento do Programa. Um elemento empírico que corrobora esta afirmação é o fato de seu Conselho não ter se empenhado em obter resultados concretos nem sobre o meio ambiente, nem sobre a reforma agrária, para ficar em dois exemplos; diversamente da maneira como se empenhou em materializar uma regulamentação do setor sem fins lucrativos.

As "organizações de defesa de interesses", tais como os sindicatos, também parecem não caber na órbita do Programa. Por exemplo, Bresser-Pereira e Grau (1999), enquadram tais entidades a uma categoria distinta que denomina "organizações corporativistas". O objetivo e função destas é agrupar segmentos no sentido de conquistar ou manter algum benefício. Essas organizações não se valem da concepção de que a sociedade civil é espaço de colaboração, ao contrário, parte da perspectiva do conflito. Não nega o Estado, dirige-se a ele para exigir quando necessário. Não critica a existência de ideologias, mas reconhece diversas delas, e até elege algumas para perseguir ou se opor.

Mixes entre organizações de perfil ativista e de defesa de interesses existem, como é o caso do MST, que, ao mesmo tempo em que defende os interesses imediatos por assentamentos, empunha a bandeira da transformação social.

Este grupo de organizações se encontram totalmente fora do foco do Comunidade Solidária e até são vítimas de repulsa, dado que tudo o que representam ou buscam representar é o que o programa rejeita enfaticamente - politização, particularismo das pautas, conflito de interesses, etc. Existem sindicatos de trabalhadores que, no contexto da segunda metade da década de 90, buscam partilhar sua posição de defesa da classe com iniciativas caritativas, tais até poderiam contar com a simpatia ou o apoio de algum programa do Comunidade, mas isso é apenas porque o sindicato deixou de agir enquanto tal, passando a operar como uma organização que atua segundo a lógica da prestação de serviço social.

Tais fatos demonstram que, em contraste ao que objetivava parecer aos olhos da sociedade, o Programa não buscou construir um novo espaço democrático, virtuoso e cidadão, identificado com a expressão "terceiro setor". A intenção real foi impulsionar uma estratégia de enfrentamento a problemas sociais que restringia a responsabilidade do governo, que envolveu o mercado e organizações públicas não estatais bem específicas. 
ABRAMOV, Oleg. Governo FHC e estratégia de parceria: retomando a análise crítica do programa Comunidade Solidária

As organizações que figuram como potenciais parceiras do Comunidade Solidária são aquelas que serão aqui denominadas "neocaritativas" ou "filantrópicas". Com relação à primeira, o prefixo "neo" é empregado para destacar a diferença destas para com as que tradicionalmente já praticavam assistência social. Os contornos de tais organizações se encaixam mais adequadamente ao que o Counidade Solidária requer, segundo os critérios selecionados por seus animadores. Tais se afirmavam no contexto dos anos 90 como um fenômeno inédito contemporâneo e em ascensão. Já as “organizações filantrópicas" são aquelas que comungam dos mesmos valores e produzem ações semelhantes, mas possuem como diferencial o tempo de existência, a tradição e, às vezes, o amadorismo. Tais sempre existiram, mesmo que em certos casos não se manifestassem em associações formais. As organizações neocaritativas envolvem métodos modernos de trabalho, disciplina organizativa, dispositivos atualizados de ação e linguagem. Já as filantrópicas raramente se valem de estratégias de atuação que primam pela permanência ou racionalidade. Entretanto, existem também aquelas tradicionais que buscaram tornar-se mais sofisticadas neste novo contexto, aprimorando sua estrutura e metodologia de trabalho e assim se tornaram mais próximas às características das neocaritativas.

Embora no discurso pareça privilegiar as organizações neocaritativas, o Comunidade Solidária não deixou de reconhecer as filantrópicas como potenciais parceiras. Portanto, na prática, o diferencial que se acentua é o das organizações que produzem assistência daquelas que reivindicam ações públicas ou defendem interesses de grupos específicos.

Organizações neocaritativas, filantrópicas, ativistas ou de defesa de interesses, podem ser igualmente consideradas integrantes do assim chamado "terceiro setor". Todas fazem parte da sociedade civil, não são governamentais, envolvem algum nível de consciência cidadã e valem-se do desprendimento voluntário. O Movimento dos Trabalhadores sem Terra, por exemplo, incorpora todas estas características, porém, não constitui um parceiro do Comunidade Solidária. Portanto, o Programa seleciona algumas modalidades e tipos de organizações em detrimento de outras. O que conta não é ser "terceiro setor". Este fato fica ainda mais evidente quando se verifica a relação estabelecida com as empresas.

De nenhuma maneira, a filantropia empresarial poderia estar incorporada a qualquer interpretação de público não estatal, antes de tudo porque a empresa constitui uma organização cujo objetivo é a obtenção de lucro. É contraditório que alguns autores do "terceiro setor", que se valem da retórica deste ser "não-lucrativo", afirmem que os projetos sociais das empresas são sua parte constitutiva. No caso da empresa, o investimento social 
objetiva aumentar o valor agregado de seu produto. Seja através de deduções fiscais ou por meio de marketing, o que orienta a filantropia empresarial é o lucro.

A "filantropia empresarial" é um fenômeno particular que se vincula a estratégias de mercado e à perspectiva-fim de maximização dos interesses da firma, e não das clientelas assistidas (PAOLI, 2002). Ainda assim, o Comunidade Solidária sempre buscou a parceria empresarial para contribuir no financiamento de boa parte de seus programas. Foi assim, por exemplo, no Programa Rede Jovem, o qual a IBM foi parceira, doando computadores para Infocentros de bairros da periferia de grandes centros. Esta dimensão demonstra que não havia apenas público não estatal envolvido, diferentemente, o mercado constituiu um importante pilar na estratégia conduzida pelo Comunidade Solidária. É saliente a contradição de sua ação para com princípios divulgados e é reveladora quanto a face da predileção pelo mercado em detrimento ao Estado.

Um empresário em particular pode ser movido por valores e daí decidir, por exemplo, produzir uma ação voluntária ou apoiar uma organização que ampare desassistidos. Neste caso, o sujeito em questão não age como um empresário, mas como um cidadão, religioso ou indivíduo consciente, não como empresário, pois, como tal, o objetivo e maximizar lucros, condição determinante para concorrer no mercado. Da mesma maneira, o objetivo fim da firma é expandir capital, de forma que uma iniciativa voluntária deve, necessariamente, estar vinculada a este propósito, do contrário não está agindo como uma firma e, de acordo com a regra de competição, torna-se ineficiente. Portanto, acreditar na desvirtuação dos propósitos da competição capitalista em nome de uma suposta "consciência cidadã" significa ignorar a dinâmica econômico-social tal como ela é.

Conclui-se, portanto, que através da intermediação na produção de parcerias entre público, privado e público não-estatal, nas proposições de ordem legal, nas estratégias de informação e com seus próprios programas, o Comunidade Solidária ajudou a estruturar um conjunto de organizações de direito privado e práticas assistenciais que servem exclusivamente para a prestação de serviços públicos. Não está no horizonte a construção de um suposto "terceiro setor" que, na prática, não representa coisa alguma; não se objetivava ampliar o espaço democrático na sociedade civil, uma vez que as democráticas negociações entre patrão e empregado e entre sociedade e governo são desacreditadas. Também não é seu fim criar qualquer tipo de laço solidário e descomprometido com interesses particulares, uma vez que as empresas lucram com a nova "face cidadã". Sua meta foi apenas contribuir para a proliferação de entidades que servem para prestar serviços em acordo com o mercado, rejeitando a intervenção direta do Estado. Isto se evidencia nos recursos que injetou nestas 
ABRAMOV, Oleg. Governo FHC e estratégia de parceria: retomando a análise crítica do programa Comunidade Solidária

organizações direta ou indiretamente e na legislação que ajudou a aprovar. Traços estes que serão analisados a seguir.

\section{COMUNIDADE SOLIDÁRIA: AÇÃO E IMPACTO}

\subsection{Marco legal e financiamento}

Da parte do Estado, o crescimento da fração interessada do "setor público não-estatal" - neocaritativa, filantrópica e empresarial - se deve a duas estratégias que envolvem a atuação do Comunidade Solidária. A primeira era a constituição de um marco legal que regulasse as atividades e organizações sem fins lucrativos e a segunda foi a transferência de recursos por meio de isenções fiscais, incentivos financeiros e parcerias com envolvimento ou não do Governo Federal.

Entre as inúmeras nomenclaturas adotadas pelas organizações e práticas filantrópicas e neocaritativas, tais como instituto, organização da sociedade civil, organização sem fins lucrativos, entidade assistencial ou mesmo ONG, apenas possui autenticidade jurídica as organizações definidas como Organização de sociedade civil de interesse público (OSCIP), Organização de utilidade pública, Organização Social (OS) e Entidade filantrópica. Estas foram objeto de regulamentação durante o governo FHC. Essa é a dimensão do marco regulatório em que, segundo autores como Baltazar (1996), o Comunidade Solidária teve um papel destacado, tendo em vista que foi seu Conselho que apresentou diversas das propostas de leis que o governo encaminhou ao Congresso Nacional.

Szazi (2006) demonstra que grande parte da legislação que sustenta juridicamente as práticas e organizações privadas sem fins lucrativos e as regulamentações sobre parcerias e isenções fiscais para fins sociais foram produzidas durante o governo FHC. Em 1998 e 2000, foram determinados os parâmetros para a concessão de certificado de entidade de fins filantrópicos. Também em 1998, o governo conseguiu aprovação da Lei que dispunha sobre o serviço voluntário, determinando que este consistia em uma atividade não remunerada prestada por pessoas físicas e entidades públicas sem que gerasse vínculo empregatício e nem obrigações trabalhistas e previdenciárias. No mesmo ano, houve a qualificação das Organizações Sociais, peça importante do projeto de reforma gerencial, posto que estas teriam prioridade na celebração de parceria com o Estado para a produção e prestação de inúmeros serviços (BRESSER-PEREIRA e GRAU, 1999). De acordo com a lei 9.637 de 15 de maio, seriam elas "pessoas jurídicas de direito privado, sem fins lucrativos, cujas atividades seriam dirigidas ao ensino, à pesquisa científica, ao desenvolvimento tecnológico, à proteção e 
preservação do meio ambiente, à cultura e à saúde, atendidos os requisitos previstos nesta lei”. No ano seguinte, a Lei 9.790 passava a qualificar pessoas jurídicas de direito privado, sem fins lucrativos, como sendo Organização da Sociedade Civil de Interesse Público (Oscip) e disciplinava o termo parceria que passava a determinar as regras de vínculo e cooperação entre elas e o Poder Público. Mais tarde seria regulamentada e alterada por uma medida provisória de 2001.

O relatório do Gerência de Estudos Setoriais - GESET (2001) informa que, em 1995, os recursos que compunham os orçamentos das organizações sem fins lucrativos provinham de receitas próprias e de doações privadas nacionais e, principalmente, estrangeiras. As fontes governamentais vinham bem atrás e não correspondiam a mais que $14,5 \%$. Na segunda metade da mesma década, há um considerável aumento da participação estatal em seu financiamento. A legislação que organiza a transferência de recursos públicos para as entidades sem fins lucrativos tem como marco a Lei 9.732 de 11 de dezembro de 1998 que alterou os dispositivos anteriores, elevando os benefícios das entidades filantrópicas na isenção de contribuição à seguridade social. Outra Lei importante neste mesmo campo é a de número 9.637 que desobrigava as entidades sem fins lucrativos em participar de processos licitatórios para realizar atividades públicas (SZAZI, 2006).

Partindo do Comunidade Solidária, o governo FHC desenvolveu diversas outras modalidades de cooperação e financiamento que contribuíram para sua expansão. Segundo Montaño (2005), pode-se considerar os seguintes exemplos: auxílios derivados diretamente do Orçamento; as subvenções voltadas a cobrir despesas de custeio destas entidades; os convênios, acordos e ajustes que, amparados pela lei, permitiam o repasse de verbas públicas para Oscips, OSs e outras; os contratos de gestão, onde a instituições firmavam contratos de prestação de serviços sem passar por concorrência pública como determinava a Lei 9.637; termos de parceria firmados pela Lei 9.790 que determinava a possibilidade do Estado repassar recursos para as entidades "parceiras"; e, por fim, a isenção tributária e a renúncia fiscal que desobrigavam as instituições filantrópicas ou de interesse público a pagar impostos, conforme determinado pela Lei 9.732.

Além dos benefícios financeiros provindos do Estado, outro componente relevante é que, ao longo dos anos 90, o investimento empresarial em iniciativas públicas não estatais cresceu. Entre 1997 e 2000, houve um crescimento na ordem de $\mathrm{R} \$ 59.346 .638$ em valores corrigidos. Em 1998, as empresas da região sudeste destinaram em torno de R \$ 3,5 bilhões para ações sociais (GESET, 2001). 
ABRAMOV, Oleg. Governo FHC e estratégia de parceria: retomando a análise crítica do programa Comunidade Solidária

\subsection{Efeitos da estratégia de parceria}

O que se verifica não é uma relação causal, onde se poderia avaliar o "público nãoestatal" como o resultado da ação do governo FHC, tal como sugere Montaño (2005) e outros. Diferentemente, o que se tem é uma "afinidade eletiva", entre as intenções do governo e o desenvolvimento de práticas e organizações privadas que proveem serviços públicos.

Além da secular existência de atividades e associações filantrópicas, um processo de expansão das organizações neocaritativas já estava em curso antes do governo FHC. Dados de 1995, apresentados no relatório da Gerência de Estudos Setoriais - GESET (2001), demonstram que já na primeira metade da década, do total de população ocupada, cerca de 2,2\% trabalhavam em atividades sem fins lucrativos. Em relação a outros países do mundo, o Brasil se encontrava abaixo da média, mas ainda assim o número era considerável. Estima-se que se somado o trabalho voluntário, naquele ano, cerca de 1.500 .000 pessoas estiveram envolvidos na área. A mesma pesquisa demonstrou que, de 1991 a 1995, teriam sido criados no Brasil cerca de 340.000 postos de trabalho neste setor, havendo uma concentração maior nos campos da educação, saúde e assistência social.

A partir do governo FHC, de acordo com dados do IPEA ${ }^{5}$, o número de fundações e associações sem fins lucrativos no Brasil se expandiu aceleradamente. Entre 1996 e 2005 o setor cresceu três vezes mais que o das organizações públicas e privadas. Enquanto a expansão das primeiras foi de $215,1 \%$ a das segundas não passou de $74,8 \%$. A Associação de Organizações Não-Governamentais $(\mathrm{ABONG})^{6}$ divulga que o total de organizações desse tipo triplicou entre 1996 e 2002, ao passar de pouco mais de 2.800 organizações para aproximadamente 8.600 em seis anos. O relatório do IBGE/IPEA (2005) sobre as associações e fundações no Brasil reforça a tese desta expansão. Entre 1996 e 2002, o número de Fundações Privadas e Associações sem Fins Lucrativos passou de 107.332 para 275.895, o que significa um aumento na ordem de $157 \%$. Ao passo que, no mesmo período, as demais entidades privadas sem fins lucrativos cresceram em $114,7 \%$.

Os números revelam que não há relação mecânica entre expansão das iniciativas e organizações públicas não estatais e a ação do governo do PSDB, porém constata-se que a disposição do governo em impulsioná-las surtiu efeito na sua intensificação.

Os alarmantes números relacionadas ao grau e abrangência da fome e miséria associado ao lastro cultural luso-cristão, que trás em si uma ética voluntarista expressa em

\footnotetext{
${ }^{5}$ Obtidos no site do IPEA http://www.ipea.gov.br/default.jsp. Acessado em 25/07/09.

${ }^{6}$ Dado obtido no site da ABONG, www.abong.org.br
} 
milhares de mobilizações e campanhas filantrópicas que já ocorriam há séculos no Brasil, criam o ambiente propício para o desenvolvimento daquilo que buscava-se convencer ser o "terceiro setor". Um outro componente importante é a disposição de entidades internacionais de direito privado em suprir de recursos as iniciativas adotadas neste sentido e organizações criadas para este fim.

Verificando dados relacionados à fome, pobreza e pobreza extrema contata-se os efeitos práticos da estratégia de parceria.

Gráfico 1 - Número de indivíduos extremamente pobres - Linha de Pobreza Baseada em Necessidades Calóricas (unidade \%)

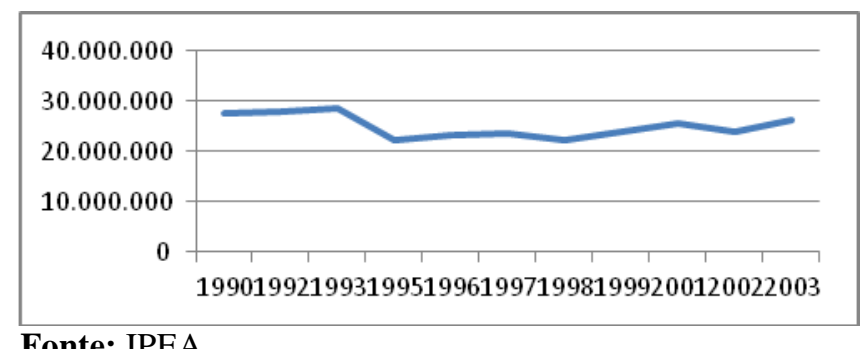

Gráfico 2 - Número de indivíduos pobres - Linha de Pobreza Baseada em Necessidades Calóricas (unidade número de pessoas)

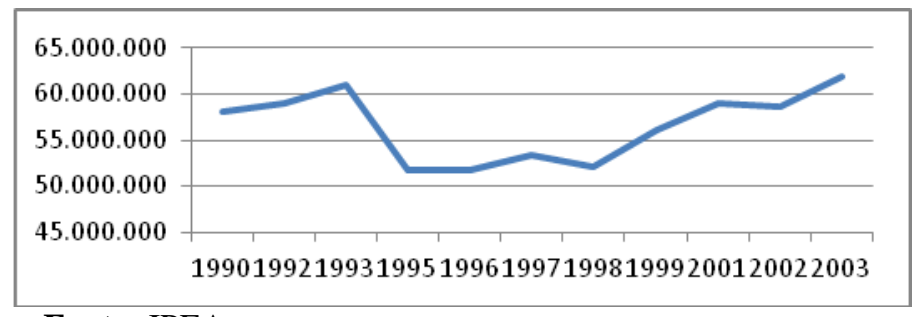

Fonte: IPEA

Gráfico 3 - Pobreza - proporção de domicílios extremamente pobres (unidade\%)

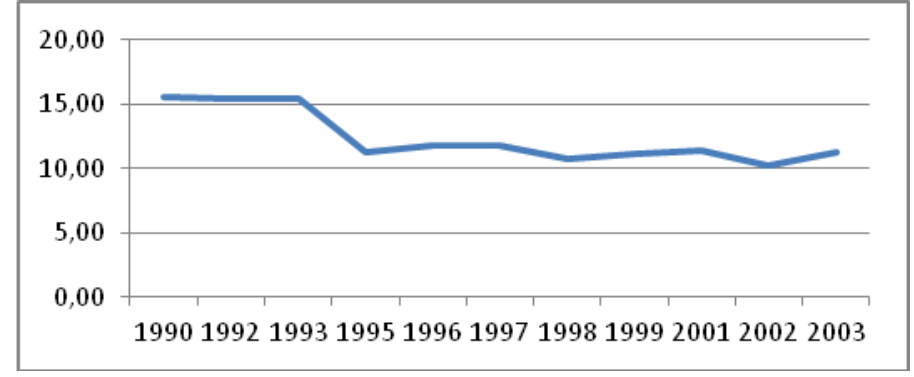

Fonte: IPEA 
ABRAMOV, Oleg. Governo FHC e estratégia de parceria: retomando a análise crítica do programa

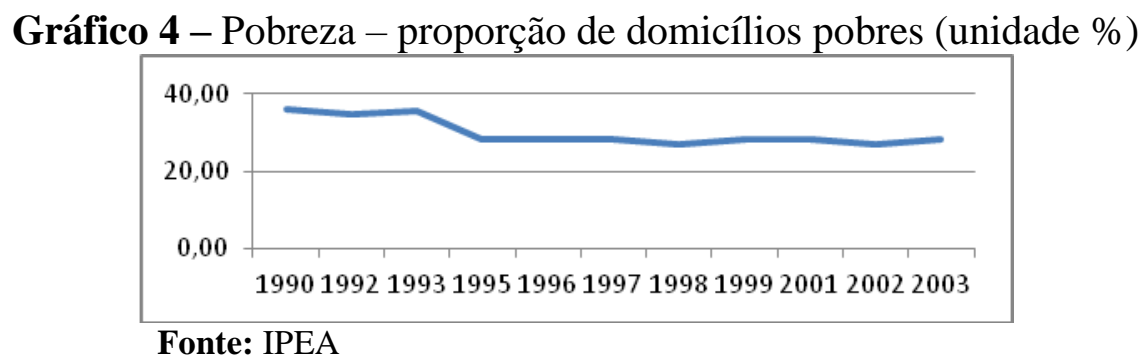

Os gráficos são esclarecedores quanto a incapacidade da estratégia de parceria em surtir efeitos de curto prazo. A variação dos indicadores destoam da expansão do 'terceiro setor". Não sendo bem sucedida no combate aos dilemas sociais agudos, a opção por tal estratégia se justifica em outras motivações. Dada a orientação geral do governo FHC citada anteriormente, é visível a funcionalidade das iniciativas públicas não estatais para com o projeto perseguido pelo governo. Uma pista interessante é o fato das mesmas agências que sugeriram o ajuste estrutural propunham políticas sociais de parceria Estado-sociedade organizada na provisão de políticas sociais.

Segundo Gusmão (1995) e Montaño (2005), o Comunidade Solidária é um componente do ajuste estrutural, uma vez que ajuda a desenvolver uma estratégia que tira da órbita do Estado a responsabilidade para com a questão social. Através do desenvolvimento daquilo que convencer ser o "terceiro setor", engendra-se um processo de remercantilização e refilantroposição do trato com os problemas sociais.

É dessa maneira que se apresenta a afinidade eletiva na qual o Estado apoia as organizações públicas não estatais, e estas assumem tarefas até então tidas como estatais. $\mathrm{O}$ governo regula, impulsiona, financia e cria facilidades diversas para tais organizações, e elas, por sua vez, desobrigam e desoneram o Estado, ao passo que os dilemas sociais vão encontrando respostas - ou pelo menos era isso o que se esperava. O problema é que tais respostas não são dadas, o que torna evidente a ineficiência da estratégia.

\section{A FALÊNCIA DA ESTRATÉGIA DE PARCERIA}

Em maio de 1996, o Conselho do Comunidade passou por uma crise que resultou na elaboração de uma carta dirigida ao Presidente FHC que reivindicava mais atenção com a questão social. As dicotomias do Comunidade, geradas pelo choque entre a orientação geral do governo e as expectativas de setores da sociedade, ocasionou tensões internas. A política macroeconômica ortodoxa era criticada por membros do Conselho e alguns como Jorge 
Eduardo Durão e Herbet de Souza (Betinho) chegaram a romper com o Programa. No segundo mandato, ocorreu uma reorganização que apontava certo deslocamento da representação social em relação ao governo. Talvez, por isso, o Comunidade passou por aquilo que os próprios envolvidos, na época, chamavam de "refundação", que se tratava de buscar modificar seu perfil institucional dando mais espaço à sociedade civil no lugar dos representantes do governo. O número de membros da sociedade presentes no Conselho passava de vinte e um para vinte e sete, e a quantidade de ministros era reduzida para quatro. A partir de então, o Conselho do Comunidade buscou abandonar o perfil de instância do governo para investir em estratégias próprias.

Em 1998, o Governo Federal criou o Bolsa-Escola; em 1999, instituiu o Programa Comunidade Ativa; e, em 2000, foi lançado o Projeto Alvorada. O traço comum aos três é o fato de se ampliar a intervenção do Estado. Há evidente reorientação que se expressa no fato do governo passar a intervir mais diretamente na distribuição de renda e na indução do desenvolvimento local nas comunidades pobres em todo o país, organizando e investindo recursos (SILVA, 2001). Simultaneamente à instalação do Comunidade Ativa, o Congresso Nacional instituiu uma "comissão de combate à pobreza" que, dentre outras, propôs uma emenda constitucional sugerindo a adição ao conjunto de políticas sociais de dispositivos de garantia a renda mínima. A partir de então foi constituído o Fundo de Combate à Pobreza, destinado a financiar ações de transferência de renda.

Tal mudança na agenda social no decurso da Era FHC, segundo Silva (2001), é explicada pela constatação de que as experiências nacionais e internacionais já mostravam na época que os problemas sociais não poderiam ser resolvidos por políticas desenvolvidas em parceria.

Silva, Guilhon, Cruz e da Silva (2001) lembram que o Comunidade Solidária tinha pouco de inovador, posto que muitos de seus princípios, práticas e objetivos já haviam sido desenvolvidos pelo Pronasol mexicano, cujos resultados são, em seu julgamento, questionáveis.

De fato, existem questões inerentes à própria eficácia, eficiência e efetividade da estratégia de parceria. Clientelas se tornam dependentes da "vontade" de empresas e cidadão atomizados para financiar ou prover políticas públicas, que é agravada pela falta de garantia de continuidade dos programas e projetos desenvolvidos.

No caso da filantropia empresarial, um dos maiores problemas é submeter as políticas às flutuações de mercado e do cálculo de rentabilidade. Ou seja, há mercantilização do 
ABRAMOV, Oleg. Governo FHC e estratégia de parceria: retomando a análise crítica do programa Comunidade Solidária

provimento posto que cabe avaliação de qual proporção o investimento social é capaz de agregar valor aos negócios.

Souza (2001) avalia que a representação da questão social pelo Programa centra-se apenas no problema econômico a ela subjacente e esquiva-se em abordar outros aspectos como os políticos, sociais, culturais e até religiosos. Segundo ela, este fato naturaliza a pobreza. Há banalização da miséria, pois acaba apresentada como um fenômeno cultural e passageiro que tem a ver até com a culpa do próprio indivíduo miserável que foi incapaz de conquistar sua parte dos benefícios da economia de mercado.

Gusmão (1995) avalia uma outra dimensão relacionada à problemática que gira em torno do Comunidade Solidária que, segundo ele, possui um cunho populista e autoritário, pois, ao enfatizar programas pontuais dirigidos aos "bolsões de pobreza", exclui a participação da sociedade nas decisões sobre investimentos, além de diminuir direitos, desmontando políticas universais preconizadas pelo Lei Orgânica da Assistência Social. Ao mesmo tempo, seus programas são marcados pela ineficiência e fragmentação.

Silva, Guilhon, Cruz e da Silva (2001), reúnem outras críticas elaboradas por diversos autores, dentre elas deve-se citar: o desmonte de órgãos de assistência social, diminuindo a responsabilidade pública pelas políticas sociais; ênfase na centralização do executivo federal, mesmo valendo-se do discurso da descentralização; prefeitos municipais como substitutos das forças sociais locais; indefinição e instabilidade de recursos que ficavam dependentes de vários ministérios; ações predominantemente focalizadas e seletivas; retorno a práticas assistencialistas e patrimoniais; oposição e inviabilização da LOAS; uma possível reedição da tradição "primeiro damista"; dentre outras.

Por fim, ao verificar um estudo de caso são perceptíveis diversos problemas relacionados ao aspecto prático da implementação das iniciativas do Comunidade Solidária. Ao analisar uma amostra de municípios do Maranhão, Silva, Guilhon e Lima (2001) localizam distorções na equivocada seleção dos municípios que recebiam os benefícios. Segundo elas, a questão se deve tanto a problemas metodológicos quanto relacionados à ingerência política. Quanto à focalização nas famílias vitimadas pela pobreza, também foram identificadas limitações na implementação dos programas que acabavam atendendo a uma parcela muito inferior da população que realmente necessitava de assistência; além disso, ficou evidente a desarticulação entre os programas diversos. As autoras concluem que tais problemas revelam os aspectos de descontinuidade, de insuficiência e de fragmentação do combate à pobreza, o que contribui para sua reprodução no lugar de ajudar a erradicá-la. 
Todas estas considerações críticas de ordem teórica e prática ajudam a fazer compreender as defasagens da estratégia de combate à pobreza efetivada pelo Programa Comunidade Solidária.

Draibe (2003) é uma das autoras que considera que, no segundo mandato, o governo definia uma nova estratégia de enfrentamento à pobreza, passando a priorizar programas que contavam com maior participação estatal. Tal como a anterior, a nova forma de combater os dilemas sociais não estava em descompasso com as diretrizes da equipe econômica, ao contrário, ela chegava a ser sugerida pelos organismos multilaterais, como por exemplo, o Banco Mundial. Inclusive, há registros de que o executivo se valeu de algumas delas como critério para ratificar acordo de renegociação de dívidas com o Banco Interamericano de Desenvolvimento.

Portanto, não havia contradição entre a nova política de distribuição de renda e a linha geral adotada pelo governo FHC para a questão social: permanecia submissa aos imperativos do ajuste econômico-administrativo e que supunha a focalização, descentralização, precarização, mercantilização e parceria. Programas como o Bolsa-Escola podem ser considerados relativamente baratos; são focalizados de modo que não oneram sobremaneira o governo e não criam passivo para o Estado, posto que pode ser operado com a máquina e funcionários já empregados nos três níveis da administração pública. Draibe (2003) exemplifica a situação ao demonstrar que, em 2002, todos os programas da Rede Social Brasileira de Proteção Social previam um gasto equivalente a apenas 3\% do PIB.

Um outro aspecto relevante e que condiz com as orientações gerais do governo é a flexibilidade dos novos programas. Devido ao fato de que não dispunham de regras rígidas, cada um podia ter seus recursos manipulados pelo executivo que detinha o poder para aumentar ou diminuir benefícios a cada negociação orçamentária.

Cabe lembrar que esta modalidade de política de distribuição não emergiu do nada. Anteriormente, por exemplo, no governo Sarney, políticas compensatórias que apresentam contornos próximos às que seriam geradas no governo FHC foram desenvolvidas, ainda que de forma muito arcaica.

Apesar das continuidades representadas por esta nova modalidade de enfrentamento a dilemas emergenciais, uma avaliação deve ser devidamente destacada: ela representa uma alternativa ao que propunha o Comunidade Solidária. Pode-se dizer que, no lugar da estratégia de parceria, era desenhada uma agenda de combate à pobreza totalmente dirigida pelo governo e financiada exclusivamente por ele. Exemplo desta é a Rede Social Brasileira 
ABRAMOV, Oleg. Governo FHC e estratégia de parceria: retomando a análise crítica do programa Comunidade Solidária

de Proteção Social que fortalecia o Bolsa-Escola e passava a financiar outros programas, tais como o Bolsa Alimentação, a Agenda Jovem e o Auxílio Gás (DRAIBE, 2003).

O fato mais proeminente é o reconhecimento do lugar que o Estado passava a ocupar. Avalia-se então que, mesmo sem observar os dados empíricos, é evidente que a estratégia de parceria para o combate à pobreza foi superada na prática. A nova estratégia representa uma reorientação da política social ao Estado. Ao contrário da política de parceria representada pelo Comunidade Solidária, a modalidade de transferência de renda centrada na responsabilidade estatal acabou perpetuando-se no governo petista posterior, ainda que com novos contornos e escopo mais amplo.

\section{CONCLUSÃO}

O comunidade solidária foi uma instituição formal, criada para efetivar uma estratégia de enfrentamento à pobreza, totalmente integrada às metas gerais do governo FHC. Ou seja, buscava soluções para dilemas sociais através de parcerias de forma a não elevar os gastos financeiros - como era determinado pela equipe econômica ortodoxa - e evitando a geração de outros passivos - de forma a não contradizer as metas de enxugamento da máquina estatal preconizadas pela reforma gerencialista.

A retórica do Comunidade Solidária baseava-se na afirmação de que, na atualidade, os dilemas sociais deveriam ser enfrentados por toda a sociedade. Frente à suposta incapacidade do Estado, os cidadãos, movidos por valores solidários e atuando individual ou coletivamente enredados pelo "terceiro setor", tornavam-se responsáveis pelo enfrentamento de mazelas como a fome e a miséria. Para tanto, supunha-se que as ideologias e os conflitos estariam tornando-se anacrônicos.

Seus pressupostos revelam a opção por negar a centralidade do trabalho nas relações sociais, sugere que na sociedade civil, cidadãos atomizados agem sem se referenciarem no Estado, ou pior, elegendo-o como oponente e de maneira acrítica em relação aos efeitos perversos resultantes da operação do mercado capitalista.

O principal propósito do Programa era impulsionar políticas emergenciais, construídas com base na parceria entre Estado e sociedade, fomentando e organizando a dimensão pública não-estatal ou o "terceiro setor”. Na prática, objetivava impulsionar certos tipos específicos de associações, comprometidas com a intervenção social através da prestação de serviços, aqui conceituadas como neocaritativas e filantrópicas. Uma contradição intrínseca ao discurso terceirosetorista se expressa na defesa filantropia empresarial, que resguarda uma orientação 
diversa da lógica do voluntariado e do comprometimento coletivo. Na prática, o Comunidade Solidária não criou um novo setor publico não-estatal, mas o impulsionou, especialmente através do financiamento direto ou indireto e da regulamentação, um tipo de intervenção social, que já vinha amadurecendo anteriormente.

Suas limitações concretas, evidenciadas por indicadores relacionados à pobreza e realçadas pela literatura crítica, demonstram sua ineficiência prática e a cumplicidade com o ajuste estrutural. A modificação realizada na agenda social durante o segundo mandato de FHC em favor da política focalizada de transferência de renda, reforça a tese de que a ineficiência da estratégia de parceria foi constatada pelo próprio governo.

\section{REFERÊNCIAS}

ALBUQUERQUE, A. C. C. de. 2006. Terceiro setor - história e gestão de organizações. São Paulo: Summus.

BRESSER-PEREIRA, L. C. 1999. Entre o Estado e o mercado: o público não estatal. In.: BRESSER-PEREIRA, L. C. e GRAU, N. (orgs) O público não-Estatal na reforma do Estado. Rio de Janeiro: FGV.

CAMPOS, E. 1995. A Lei Orgânica da Assistência Social frente ao Programa Comunidade Solidária. Cadernos de Textos de Serviço Social da UNAMA. Belém.

CARDOSO, R. 1995. Mudança sociocultural e participação política nos anos 80. In: SOLA, L. e PAULANI, L. (orgs). Lições da década de 80. São Paulo: EDUSP.

CARDOSO, R. 2005. Fortalecimento da sociedade civil. In.: IOSCHPE, E. B. (org.). $3^{o}$ Setor desenvolvimento social sustentado. Rio de Janeiro: Paz e Terra / GIFE.

CARDOSO, R.; O., M. e FRANCO, A. 2000. Um novo marco de referência para o envolvimento do Estado e da sociedade civil com o desenvolvimento social. Publicação do Programa Comunidade Solidária. Brasília.

COELHO, S. de C. T. 2002. Terceiro setor - um estudo comparado entre Brasil e Estados Unidos. São Paulo: SENAC.

DEMO, P. 2001. Brincando de solidariedade: política social de primeira-dama. In.: SILVA, M. O. da S. e (org.). O Comunidade Solidária: o não-enfrentamento da pobreza no Brasil. São Paulo: Cortez.

DRAIBE, S. 2003. A política social no período FHC e o sistema de proteção social. Tempo Social, vol. 18, $n^{\circ}$ 52. São Paulo.

FERNANDES, R. C. 1994. Privado, porém público: terceiro setor na América Latina. Rio de Janeiro: Dumará.

FERNANDES, R. C. 2005. "O que é o terceiro setor". In.: IOSCHPE, E. B. (org.). $3^{o}$ Setor desenvolvimento social sustentado. Rio de Janeiro: Paz e Terra / GIFE. 
ABRAMOV, Oleg. Governo FHC e estratégia de parceria: retomando a análise crítica do programa Comunidade Solidária

GESET - Grupo de Estudos Setoriais/BNDES. 2001. Terceiro setor e desenvolvimento social. www.bndes.org .br. Acessado em: 10/05/08.

GUSMÃO, R. 1995. A assistência no contexto do governo neoliberal. Anais VIII Congresso Brasileiro de Assistentes Sociais, $n^{\circ}$ 8. Salvador.

LOBO, T. 2002. Comunidade Solidária: estratégia para o desenvolvimento social. VII Congreso Internacional del CLAD sobre la Reforma del Estado y de la Administración Pública. Lisboa.

MONTAÑO, C. 2005. Terceiro setor e questão social - crítica ao padrão emergente de intervenção social. São Paulo: Cortez.

NAVES, R. 2003. Novas possibilidades para o exercício da cidadania. In.: PINSKY, J. e PINSKY, C. B. (org.). História da cidadania. São Paulo: Contexto.

PAOLI, M. C. 2002. "Empresas e responsabilidade social: os enredamentos da cidadania no Brasil". In.: SANTOS, B. de S. Democratizar a democracia: os caminhos da democracia participativa. Rio de Janeiro: Civilização Brasileira.

PELIANO, A. M. T. M.; RESENDE, L. F. de L. e BEGHIN, N. 1995. O Comunidade Solidária: uma estratégia de combate a fome e à pobreza. www.ipea.gov.br. Acessado em 30/07/09.

PERES, T. H. de A. 2005. Comunidade Solidária: a proposta de um outro modelo para as políticas sociais. CIVITAS - Revista de Ciências Sociais, vol. 5, $n^{o} 01$. Porto Alegre.

SILVA, O. da S. e 2001. Introdução. In.: SILVA, M. O. da S. e (org.). O Comunidade Solidária: o não-enfrentamento da pobreza no Brasil. São Paulo: Cortez.

SILVA, O. da S. e, GUILHON, M. V. M., CRUZ, G. G. da e DA SILVA, A. M. 2001. Comunidade Solidária: contradições e debilidades do discurso. In.: SILVA, M. O. da S. e (org.). O Comunidade Solidária: o não-enfrentamento da pobreza no Brasil. São Paulo: Cortez.

SILVA, O. da S. e, GUILHON, M. V. M. e LIMA, V. F. S. A. 2001. A focalização fragmentadora e a insuficiência do comunidade solidária no enfrentamento da pobreza: estudo de um caso no nordeste. In.: SILVA, M. O. da S. e (org.). O Comunidade Solidária: o nãoenfrentamento da pobreza no Brasil. São Paulo: Cortez.

SOARES, L. T. 2004. Questões pendentes na configuração de um pensamento social: uma síntese. www.outrobrasil.net. Acessado em: 09/07/07.

SOUZA, M. do S. A. de 2001. A representação da questão social no programa Comunidade Solidária. In.: SILVA, M. O. da S. e (org.). O Comunidade Solidária: o não-enfrentamento da pobreza no Brasil. São Paulo: Cortez.

SKOCPOL, Theda. Bringing the State back in: Strategies of analysis in current research. In: EVANS, Peter; RUESCHMEYER, Dietrich; SKOCPOL, Theda. Bringing the State back in. New York: Cambridge University Press, 1985. 
Revista Eletrônica de Ciência Política, vol. 7, n. 2, 2016

SKOCPOL, Theda. Protecting Soldiers and Mothers. Cambridge/Londres: Harvard University Press, 1995.

SZAZI, E. 2006. Terceiro setor - regulação no Brasil. São Paulo: GIFE/ Petrópolis.

TEODOSIO, A. dos S. de S. 2002. Pensar pelo avesso o terceiro setor - mitos, dilemas e perspectivas da ação social organizada nas políticas sociais. Revista Lusotopia. 